\title{
The difference in pediatric blood pressure between middle childhood and late childhood prior to dental treatment
}

\author{
Fitri Anissa Syaimima Bt. Syaiful Azim*, Arlette Suzy Puspa Pertiwi*, Rosiliwati \\ Wihardja**
}

* Department of Pedodontics Faculty Of Dentistry Universitas Padjadjaran
${ }^{* *}$ Department of Oral Biology Faculty Of Dentistry Universitas Padjadjaran

\section{ABSTRACT}

Every child will go through several stages in his or her life. They are different from each other as they are in the process of development of cognition, physics, emotion, and personality. For many children, a visit to the dentist can raise their anxiety. This anxiousness will lead to stress that influences the cardiovascular function in the body. The purpose of this research was to determine the difference in pediatric blood pressure between middle childhood and late childhood prior to dental treatment. This research was a clinical trial, pure experimental study. The sample consisted of 30 children within the range of 4-12 years old where they were divided into two groups of age; middle childhood (4-7 years old) and late childhood (8-12 years old). The blood pressures were measured before any dental treatment began and the values were recorded. The data were then analyzed using the One-Sample T-Test analysis. The results of blood pressure in middle childhood and late childhood were compared to the average mean values for each age group. It showed that there was a significant difference in the systolic pressure, which was found higher in the middle childhood group compared to the late childhood. From the result can be concluded that there was a difference in the pediatric blood pressure between middle childhood and late childhood prior to dental treatment.

Keywords: Anxiety, middle childhood, late childhood, dental treatment, blood pressure

\section{INTRODUCTION}

It is a fact that working with children is different from working with the adults. This can be challenging to a dentist in treating them because children are not all alike and they are in the process of developing language, intellect, motor skills, personalities and undergoing new experiences of life. The ages at which specific abilities develop vary. To provide qualified dental services for children, it is necessary for the dentist to have some basic knowledge of child development to better understanding on their respective developmental level. ${ }^{1}$

The most important thing to consider is the child's development stage. There are many different understanding regarding the age ranges in the childhood. From a general point of view, the term childhood is non-specific and can imply a varying range of years in human development. Developmentally, it refers to the period between infancy and adulthood. 
Middle childhood is referring to a period where the children continue to grow rapidly and begin to develop fine motor skills. Physical changes in the early childhood accompanied by rapid changes in the child's cognitive and language development. Language is a powerful tool to enhance the cognitive development. Children use language to communicate with others. From the ages three to five, the growth in socio-emotional skills includes the formation of peer relationships, gender identification and the development of a sense of right or wrong. Children of this age group range between the toddlers to adolescence. The period ranges from ages of three to late six years old until an early of seven years.

In general context, the years between age three to six often referred to as the preschool years, and the children are called preschoolers. ${ }^{2}$ In accordance with Piaget's theory, they were categorized into the second stage which is a preoperational stage. Children in this stage are characterized by magical thinking, egocentrism and perception dominated contemplation. ${ }^{3} \mathrm{~A}$ child's inability to view a situation from any other perspective besides his own is called egocentrism. Towards the end of this stage, children begin to demonstrate somewhat logical thinking and begin to realize that perspectives besides their own do exist.

Late childhood is a period after a child had gone through the process of development in the middle childhood. The children in this age of group are more developed in many aspects than the previous stage. In psychoanalytic theory by Sigmund Freud, this period was labeled as the period of latency where the sexual and aggressive urges were repressed. During this period, the physical development was less dramatic until the onset of puberty. ${ }^{3}$ As with physical development, the cognitive development is slow and steady, the children are building upon the skills gained in the early childhood and preparing for the next phase of their life. In this period, their cognitive development is far more mature compared to previous year. This period is the time when a child can gain enthusiasm to learn and to work since achievement is a motivating factor towards building competence and self-esteem.

On the whole, this is the period of a child's schooling where it starts from the ages of seven and above. Referring to Piaget, the children are in the concrete operational stage where it ranges from the ages of seven to twelve. ${ }^{2}$ As noted earlier, children begin to display somewhat logical thinking towards the end of the preoperational stage. Piaget suggests that in the concrete operational stage, a child's thought process becomes organized and integrated with one another. These larger thought processes which are also known as operation, allow children to think logically. ${ }^{3}$

According to Piaget, youth develop the morality of cooperation, at the age of ten years or older. The children develop a morality of cooperation they realize that to create a cooperative society people must work together to decide what is acceptable, and what is not. ${ }^{4}$ Piaget believed that youth at this age begin to understand that morals represent social agreements between people and were intended to promote the common good.

For example, children over the age of eight can usually tolerate extraction better than those of younger age when they are given a brief explanation of the procedure before the appointment. Children under the age of eight usually need a modification from the above explanation which is at their level of comprehension and given immediately before extraction. ${ }^{5}$ For many children, a trip to the doctor or dentist is a stressful experience. The sensory environment in dentists' office for examples the sound, smell, and light associated with the clinical setting can cause a child's anxiety levels to rise.

Stress affects our bodies causing emotional discomfort. Our bodies react by releasing stress hormones known as adrenaline and cortisol into the blood. These hormones prepare the body for the 'fight or flight' response by making the heart beat faster and constricting blood vessels to get more blood to the core of the body instead of the extremities. Vasoconstriction and increase in heart rate raise blood pressure, but only temporarily; when the stress reaction eliminated, blood pressure returns to its pre-stress level. This condition is called situational stress, and its effects are short-lived and disappear when the stressful event is over.

Children may have a different perception when they come to the dental clinic. The younger ones may assume the dentist as a threatening 
person if they have seen other children crying after treatment. This situation may become a stressful experience for them, and their anxiety level may rise. Consequently, this will affect their physiological condition, causing their blood pressure to rise temporarily. ${ }^{6}$

This experience may become reversed for older children. They can understand the situation and may give better cooperation to the dentist. They may have a little nervousness, but they will try to cope with it. Therefore, the rise in blood pressure is insignificant. The researcher wants to do this research to find if there any difference of blood pressure between middle childhood and late childhood.

This research was conducted at Pedodontic Clinics of Faculty of Dentistry Universitas Padjadjaran Dental Hospital (RSGM). The researcher chose this hospital to conduct her study because of several reasons. In Bandung city, there are only two dental hospitals in town, and the amount of pediatric patients who visit Pedodontic Clinics of Faculty of Dentistry Universitas Padjadjaran Dental Hospital is much higher than the other dental hospital. There are also more facilities and equipment for dental procedures. Not only that, the environment of Pedodontic Clinics of Faculty of Dentistry Universitas Padjadjaran Dental Hospital is nice and colorful, thus appropriate for children.

\section{METHODS}

This study was a descriptive study in which the children's blood pressure was measured prior to dental treatment.

The population used in this research were patients attended the Pedodontic Clinics of Faculty of Dentistry Universitas Padjadjaran Dental Hospital, Bandung, Indonesia. The sampling method used in this study was a consecutive sampling technique. The samples were 30 children between the ages of 4-12 years old. All samples were divided into two groups based on their age range. The first group was comprised of the children whose ages were from 4-7 years old, also called as middle childhood group. The second group known as the late childhood group was comprised of 15 children aged between 8-12 years old. The children were selected based on the inclusion criteria as follows: children either boys or girls; aged in the range of 4-12 years old; children who visited the dental clinic for the first time; neither blind nor deaf; not having any systemic disease. A measurement chart to record the readings of blood pressure was used in this research.

\section{RESULTS}

The research was conducted towards as much as 30 subjects, comprised of children in the ages between 4-12 years old which were then divided into two groups. The first group was the middle childhood comprised of as much as 15 children aged between 4-7 years old while the second group was the late childhood comprised of as much as 15 children in the aged between 8-12 years old. The research was performed at Pedodontic Clinics of Faculty of Dentistry Universitas Padjadjaran Dental Hospital, Bandung, Indonesia. The subjects were selected based on the criteria stated previously.

Blood pressure was measured right after the subject was seated on the dental chair before any dental treatment began. The readings were taken three times on each subject to get the average value for blood pressure reading. After that, the average systolic and diastolic pressure which was obtained from this study was later compared to the average mean value of blood pressure for each age group.

For the middle childhood group, the result was compared to $100 / 60 \mathrm{mmHg}$ as it was the average mean for systolic and diastolic blood pressure for children in this age group. For the late childhood, the result was compared to $110 / 65 \mathrm{mmHg}{ }^{2}$

Table 1 showed the results for blood pressure measurements; systolic and diastolic pressure when the subjects were seated on the dental chair prior to the commencement of dental treatment. The result of the systolic pressure for children in the middle childhood group aged from 4-7 years old was $111.69 \mathrm{mmHg}$, while for diastolic pressure was $68.62 \mathrm{mmHg}$. The results were higher compared to the ideal or average mean values of systolic and diastolic pressure for children in the ages of 4-7 years old which was $100.00 \mathrm{mmHg}$ for systolic pressure and 60.00 $\mathrm{mmHg}$ for diastolic pressure. While for the late 


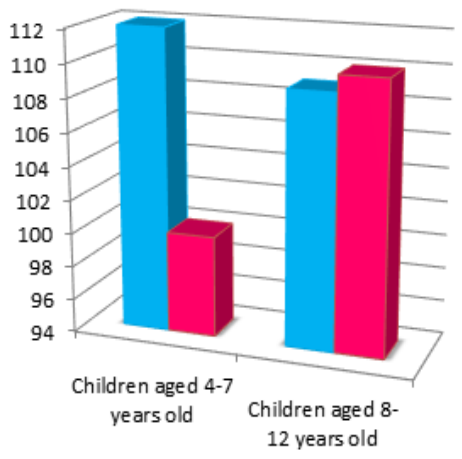

Figure 1. Chart of mean systolic pressure between two groups compared to average mean value of systolic blood pressure for each group

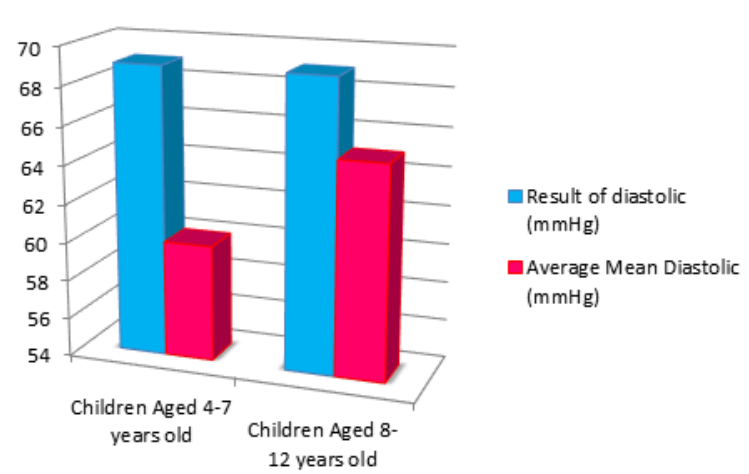

Figure 2. Chart of mean diastolic pressure between two groups compared to average mean value of diastolic blood pressure for each group

Table 1. The result of systole and diastole measurement on each group compared to average mean values of systole and diastole for each age group

\begin{tabular}{cccccc}
\hline \multicolumn{5}{c}{ Age 4-7 } & \multicolumn{2}{c}{ Age 8-12 } \\
\hline & $\mathrm{n}$ & Results & Average Mean Value & Results & Average Mean Value \\
\hline Systole & 15 & 111.69 & 100.00 & 109.13 & 110.00 \\
Diastole & 15 & 68.62 & 60.00 & 68.91 & 65.00 \\
\hline
\end{tabular}

Table 2. One sample t-test for systolic pressure with test value $=100, t$-table, $t$-value and $p$-value for group 4-7 years old children

\begin{tabular}{cccccccc}
\hline \multicolumn{7}{c}{ Test Value $=100$} \\
\hline & $\mathrm{n}$ & Mean & SD & t-value & p-value & t-table & Result \\
\hline Systolic Pressure & 15 & 111.6887 & 7.43737 & 6.087 & 0.000 & \pm 2.145 & $\mathrm{H}_{\mathrm{a} 1}$ accepted \\
\hline
\end{tabular}

Table 3. One sample $t$-test for systolic pressure with test value $=110$, $t$-table, $t$-value and $p$-value for group 8 -12 years old children

\begin{tabular}{cccccccc}
\hline \multicolumn{7}{c}{ Test Value $=110$} \\
\hline & $\mathrm{n}$ & mean & SD & $\mathrm{t}$-value & $\mathrm{p}$-value & t-table & Result \\
\hline Systolic Pressure & 15 & 109.1327 & 8.52450 & -0.394 & 0.699 & \pm 2.145 & $\mathrm{H}_{\mathrm{o} 2}$ accepted \\
\hline
\end{tabular}

Table 4. One sample t-test for diastolic pressure with test value $=60$, $t$-table, $t$-value and $p$-value for group 4-7 years old children

\begin{tabular}{cccccccc}
\hline \multicolumn{8}{c}{ Test Value $=60$} \\
\hline & $\mathrm{n}$ & mean & $\mathrm{SD}$ & $\mathrm{t}$-value & $\mathrm{p}$-value & t-table & Result \\
\hline Systolic Pressure & 15 & 68.6220 & 6.81005 & 4.903 & 0.000 & \pm 2.145 & $\mathrm{H}_{\mathrm{a} 1}$ accepted \\
\hline
\end{tabular}

Table 5. One sample t-test for diastolic pressure with test value $=65, t$-table, $t$-value and $p$-value for group 8-12 years old children

\begin{tabular}{cccccccc}
\hline \multicolumn{7}{c}{ Test Value $=65$} \\
\hline & $\mathrm{n}$ & mean & $\mathrm{SD}^{*}$ & $\mathrm{t}$-value & $\mathrm{p}$-value & t-table & Result \\
\hline Systolic Pressure & 15 & 68.9100 & 6.51306 & 2.325 & 0.036 & \pm 2.145 & $\mathrm{H}_{\mathrm{a} 2}$ accepted \\
\hline
\end{tabular}

Note SD = Standard Deviation, $\mathrm{n}=$ Total sample

childhood group comprised of the children from the ages 8-12 years old, the results were 109.13 $\mathrm{mmHg}$ for systolic pressure and $68.91 \mathrm{mmHg}$ for diastolic pressure. From Table 1 seen that there was a higher value of reading when compared to the ideal blood pressure value for children in the 
ages of 8-12 years old; $110.00 \mathrm{mmHg}$ for systolic pressure and $65.00 \mathrm{mmHg}$ for diastolic pressure.

Table 2 showed the mean and standard deviation of the One-Sample T-Test, also included the test value, t-table, t-value and $\mathrm{p}$-value of systolic pressure for children between the ages of 4-7 years old. The average of the systolic pressure was compared to test the value of $100 \mathrm{mmHg}$ which was the ideal average of the systolic blood pressure for children in the middle childhood. To prove the difference between the result of this study and the ideal mean systole, let $\mathrm{H}_{01}$ equal to no significant difference in systole reading between the two events, while $\mathrm{H}_{\mathrm{a} 1}$ was equal to a significant difference in systole reading between the two events. We choose the level of significance, alpha, $\alpha=5 \%$. The criteria for this test was $\mathrm{H}_{01}$ was not accepted if the $a<$ sig, and if the $t$-value $>t$ table, and the t-value<-t-table. Since the $p$-value was 0.000 , which was too small and the t-value (6.087) > t-table (2.145), therefore, $\mathrm{H}_{\mathrm{o}}$ was not accepted. The Ha1 was accepted for this result. In other words, at the $a=5 \%$, there was a significant difference in the result of the average value of the systolic pressure in this study compared to the test value.

Table 3 showed the average and standard deviation of the One-Sample T-Test also included the test value, $t$-value, $t$-table and $p$-value of the systolic reading for children in the ages of 8-12 years old. The average of the systolic pressure was compared to the value of $110 \mathrm{mmHg}$ which was the ideal average mean systolic blood pressure for children in the late childhood. To prove the difference between the result of this study and the ideal mean systole, let $\mathrm{H}_{\mathrm{o} 2}$ equal to no significant difference in the systolic reading between the two events, while $\mathrm{H}_{\mathrm{a} 2}$ equal to a significant difference in the systolic reading between the two events. We choose the level of significance, alpha, $a=5 \%$. The criteria for this test, $\mathrm{H}_{\mathrm{o} 2}$ was not accepted if the $a<$ sig. Since the $p$-value was 0.6999 , which was larger than 0.05 and the t-value $(-0.394)>$ t-table (-2.145), therefore, $\mathrm{H}_{\mathrm{o} 2}$ was accepted. In other words, at the $a=5 \%$, there was no significant difference in the result of the average systolic pressure in this study compared to the test value.

Table 4 showed the average and standard deviation of the One-Sample T-Test also included the test value, t-table, t-value and $\mathrm{p}$-value of diastole of children between the ages of 4-7 years old. The average of diastolic pressure was compared to the test value of $60 \mathrm{mmHg}$ which was the ideal average diastolic blood pressure for children in the middle childhood. To prove the difference between the result of this study and the ideal mean diastolic, let $\mathrm{H}_{01}$ equal to no significant difference in diastolic reading between the two events, while $\mathrm{H}_{\mathrm{a} 1}$ was equal to a significant difference in diastolic reading between the two events. We choose the level of significance, alpha, $a=5 \%$. The criteria for this test, $H_{01}$ was not accepted if the $a<s i g$ and if the $t$-value $>t$ table, and the t-value<-t-table. Since the $p$-value was 0.000 which was too small and the t-value (4.903) > t-table (2.145), therefore, $\mathrm{H}_{01}$ was not accepted. The $\mathrm{H}_{\mathrm{a} 1}$ was accepted in this result. In other words, at the $a=5 \%$, there was a significant difference in the result of the average diastolic pressure in this study compared to the test value.

Table 5 showed the average and standard deviation of the One Sample t-test also included the test value, t-table, t-value and $p$-value of diastole of children age 8-12 years old. The average of diastolic pressure was compared to the test value of $65 \mathrm{mmHg}$ which was the ideal average of diastolic blood pressure for children in the late childhood. To prove the difference between the result of this study and the ideal mean diastole, let $\mathrm{H}_{\mathrm{o} 2}$ equal to no significant difference in diastole reading between the two events, while $\mathrm{H}_{\mathrm{a} 2}$ was equal to a significant difference in diastole reading between the two events. We choose the level of significance, alpha, $a=5 \%$. The criteria for this test was $\mathrm{H}_{02}$ not accepted if the $\mathrm{a}<\mathrm{sig}$ and if the t-value $>$ t-table, and the t-value<-t-table. Since the $p$-value was 0.036 which was smaller than the alpha, and the t-value (2.325) > t-table (2.145), therefore, $\mathrm{H}_{\mathrm{o} 2}$ was not accepted. The $\mathrm{H}_{\mathrm{a} 2}$ was accepted in this result. In other words, at the $\mathrm{a}=$ $5 \%$, there was a significant difference in the result of the average diastole in this study compared to the test value.

\section{DISCUSSION}

The purpose of this research was to determine the difference of pediatric blood pressure between the middle childhood and the late childhood. As stated in the previous chapter, 
we consider that the children of the ages between 4-7 years are in the middle childhood while for children between the ages of 8-12 years fall into the late childhood. This grouping of ages was done by the researcher based on Piaget's theory of cognitive development.

The result of this study shows the blood pressure was higher in the middle child's group compared to the children in the late childhood. Based on the result, for a group of children from ages 4-7 years, there was a significant increase in the systolic and diastolic reading, which are $111.69 \mathrm{mmHg}$ in systolic pressure and $68.62 \mathrm{mmHg}$ in diastolic pressure compared to its average mean values of blood pressure, 100/60 mmHg.

As stated before, based on Piaget's theory, the thought pattern of the children in preoperational stage are not well developed, being egocentric, unable to encompass another's point of view, single tracked, inflexible and emotional phase being less stable. ${ }^{7}$ They tend to feel anxious easily, stressed and fear of something new. At this preoperative stage, the child can only focus on the perceptual dimensions and finds it hard to comprehend the differences between similar situation. ${ }^{8}$ For example, a child who was once hurt by the prick of a needle would find it difficult to understand that a dental needle is different and that the method of application may not hurt as the others do. ${ }^{9}$ At this stage, the perceptual illusions are believed to be predominant over logical reasoning. ${ }^{8}$

Also, in the medical term, there is a term called white-coat effect or white-coat hypertension. It is a stress-induced syndrome found in patients who experience an elevation in blood pressure when being examined by healthcare personnel, but otherwise, have normal blood pressure. ${ }^{10}$ The main cause of this syndrome is anxiety. It can happen with people of any ages and gender including children. A child who had visited the dental clinic for the first time may have experienced this syndrome. With the clinical surrounding, they may feel anxious because of the setting of instruments, the new environment, the smells of the clinic, the new people, the maskedpeople consisting of dental staffs and dentists. Not only that, plus the influences from their friends and family members about the bad experiences in the dental clinic, may raise their anxiety and nervousness to meet the dentist. In this situation, the body stimulates the 'fight or flight' response and causes an increase in the blood pressure. In fact, the rise in blood pressure should not be misinterpreted for the presence of hypertension. In this study, this syndrome was seen as being one of the factors that affect the rising of the blood pressure in children mostly the younger ones.

As for children between the ages of 8-12 years old, the results were $109.13 \mathrm{mmHg}$ for systolic pressure and $68.91 \mathrm{mmHg}$ in diastolic pressure. The average mean of blood pressure in children of the ages between 8-12 years is $110 / 65$ mmHg. ${ }^{2}$ From the statistical analysis, in place of a systolic pressure reading, $\mathrm{H}_{\mathrm{o} 2}$ was accepted with the level of significance $a=5 \%$. It showed that there was no significant difference between the results and the average mean value for children in the ages of 8-12 years. Whereas for the diastolic pressure reading, $\mathrm{H}_{\mathrm{a} 2}$ was accepted.

As stated before, children in the late childhood are grouped into the concrete logical stage based on the Piaget's theory of cognitive development. They can apply logical reasoning, consider other people's point of view, and assess more than one aspect of particular a situation. ${ }^{7}$ Furthermore they also give more cooperation on the dental chair. ${ }^{9}$ The emotional state is more stable than the children of the preoperational stage where their ability to self-control is better developed. Children in this age group may feel anxious when undergoing dental treatment, but with their thinking and behavior level, they might be able to control their anxiety.

Cognitive development and maturation are the keys to the success of cognitive strategies. ${ }^{2}$ As a child matures, he or she develops a broader vocabulary plus witnesses a variety of environment. These increases the child's ability to communicate with people and manage feelings more maturely sophisticatedly. With the success of coping skills in the cognitive development, the child tends to gain self-management in a stressful situation like anxiousness and pain of being treated by the dentist. ${ }^{2}$ In general, the pain threshold tends to decline, and the selfmanagement of pain becomes more effective with increasing age. ${ }^{11}$ This phenomenon results from the interaction of multiple factors including the maturation of coping skills, appreciation of self- 
control and social influences. ${ }^{2}$

Children in preschool period typically reported more fear regardless the situation, whereas children in schooling period inhibit the behavioral expression of fear or pain. The younger children are more likely to demonstrate anxiety while separating with the parents compared to the older ones. They are generally more upset by and cooperate less with medical and dental procedures. It has been proofed that unpleasant experience with injections may bring the child into the dental situation with greater anxiety. ${ }^{12}$

In the study by Rayen on the evaluation of physiological and behavioral measures regarding dental anxiety during sequential dental visits in children, based on the result, they concluded that children from 4-5 years of age have greater anxiety and fear of the unknown and these are expected to decrease in older children. ${ }^{13}$ Therefore in this research, the outcomes of a blood pressure reading in the children aged from 8-12 years are lower than the younger ones as expected. Not only that, but they also concluded that the heart rate and blood pressure acted as a reliable indicator of stress and anxiety.

Studies conducted by Messer J.G. related to stress in dental patients undergoing routine procedure confirms that physiological changes occur in the body as a result of the anxiety and stress during the dental treatment. ${ }^{14}$ This result was verified by Rayen stated that there was a significant difference in systolic and diastolic pressure during the dental treatment. ${ }^{13}$

Age is one of the variables that are related to dental anxiety or fear in pediatric populations. This study has proved that there a was a relationship between age and dental anxiety. In this study, the changes in blood pressure level represented the stress levels of a child before undergoing dental treatment. In this research, it showed that children in the middle childhood have higher changes in blood pressure compared to the children in the late childhood. This assumption was supported by Klinberg, wherein their study, they found that the younger children have higher anxiety levels than the older children. ${ }^{15}$

Also, the studies conducted by Rayen further supported this study that there was a relationship between age and dental anxiety. ${ }^{13}$

Similar to the study conducted by Klinbergh, where they evaluated the prevalence of dental fear and anxiety (DFA) and dental behaviour management problems (DBMP) in children and adolescents, and their relationships to age, sex, general anxiety, temperament, and general behavioural problems..$^{15}$ From the results, it shows a decrease in DFA and DBMP with age. It may thus reflect normal psychological development. The younger children's understanding of dental treatment differ from older children's perception, plus, they have fewer experiences from dental care implying more novel and fear-provoking situations. Pain, discomfort, and anxiety are abstract phenomena and coping with them requires advanced cognitive skills as well as a capacity for effortful control and emotion regulation that the young child is not yet mature enough to fully manage. ${ }^{15}$

\section{CONCLUSION}

According to the result of the research, it can be concluded that there was a difference in pediatric blood pressure between the middle childhood and the late childhood. The blood pressure value of children in the middle childhood was higher than children in the late childhood prior to the dental treatment began due to stress and anxiety.

\section{REFERENCES}

1. Cameron AC, Widmer RP. Handbook of Pediatric Dentistry. $3^{\text {rd }}$ ed. Edinburg. St. Louis: Mosby Elsevier; 2008. p. 9-32.

2. Pinkham JR. Pediatric Dentistry: Infancy Through Adolescence. $4^{\text {th }}$ ed. Philadelphia: Saunders-Elsevier; 2005. p. 99-479.

3. Kliegman R, Behrman R, Jenson $H$, Stanton B. Nelson Textbook of Pediatrics. $18^{\text {th }}$ ed. Philadelphia: Saunders Elsevier; 2007. p. 33-59.

4. MentalHelp.Net [homepage on internet]. New York: Oswalt A. Jean Piaget's theory of cognitive development. [cited 2010 Nov]. Available from: https: //www.mentalhelp.net/ articles/jean-piaget-s-theory-of-cognitivedevelopment/.

5. Luke LS, Barber TK. Postgraduate Dental Handbook: Pediatric Dentistry. $1^{\text {st }}$ ed. St. Louis: Mosby-Elsevier; 1982. p. 1172-7. 
6. VeryWell [homepage on internet]. New York: Weber C. 2008. Does anxiety cause high blood pressure? [cited 2012 Mar]. Available from: https: / / www.verywell.com/does-anxietycause-high-blood-pressure-1764075.

7. Welbury R, Duggal MS, Hosey MT. Paediatric Dentistry. $3^{\text {rd }}$ ed. Oxford: Oxford University Press; 2005. p. 19-37.

8. Piaget J, Inheider B. The psychology of the child. $3^{\text {rd }}$ ed. New York: Ingram Publisher Services US; 1972.

9. Folayan MO, Kolawole KA. A critical appraisal of the use of tools for assessing dental fear in children. Afr J Oral Health. 2004;1(1):54-63.

10. Tortora GJ, Derrickson B. Principle of Anatomy and Physiology. $12^{\text {th }}$ ed. Hoboken: John Wiley \& Sons, Inc; 2009. p. 772-83.

11. Katz ER, Kellerman J, Siegel SE. Behavioral distress in children with cancer undergoing medical procedures: development considerations. J Consult Clin Psychol. 1980 Jun;48(3):356-65.

12. Melamed BG. Methodological needs and behavioral research with child dental patients. Anesth Prog. 1986 Jan-Feb;33(1):34-40.

13. Rayen R, Muthu MS, Chandrasekhar Rao R, Sivakumar N. Evaluation of physiological and behavioral measures in relation to dental anxiety during sequential dental visits in children. Indian J Dent Res. 2006 JanMar;17(1):27-34.

14. Messer JG. Stress in dental patients undergoing routine procedure. J Dent Res. 1977 Apr;56(4):362-7.

15. Klingberg G, Broberg AG. Dental fear/ anxiety and dental behaviour management problems in children and adolescents: a review of prevalence and concomitant psychological factors. Int J Paediatr Dent. 2007 Nov;17(6):391-406. 